\title{
Sustaining a Rational Disagreement
}

\author{
Christoph Kelp \\ Institute of Philosophy, University of Leuven \\ christoph.kelp@hiw.kuleuven.be \\ Igor Douven \\ Faculty of Philosophy, University of Groningen \\ i.e.j.douven@rug.nl
}

\begin{abstract}
Much recent discussion in social epistemology has focussed on the question of whether peers can rationally sustain a disagreement. A growing number of social epistemologists hold that the answer is negative. We point to considerations from the history of science that favor rather the opposite answer. However, we also explain how the other position can appear intuitively attractive.
\end{abstract}

Disagreements are numerous in this world. There are disagreements about matters of taste: some people like minimalist art while others do not; some like oysters, others detest them. However, the scope of disagreement extends beyond the realm of the subjective, well into the realm of the objective. People disagree for instance about matters political—should taxes be raised? — religious—does God exist? — philosophical—do we have freedom of the will? —and scientific-is the universe infinite?

While it is fairly uncontroversial that people disagree in a variety of areas of thought, there is an interesting normative question concerning the epistemic status of such disagreements. More specifically, the question has been raised whether there can ever be rational disagreements among agents who take each other to be epistemic peers on a certain question. To say that a number of agents are epistemic peers concerning a question, $Q$, is to say, first, that they are equally well positioned evidentially with respect to $Q$, second, that they have considered $Q$ with equal care, and, third, that they are equally gifted with intellectual virtues, cognitive skills and the like. ${ }^{1}$ For epistemic peers to rationally disagree on $Q$ is for them to justifiably hold different doxastic attitudes concerning $Q .{ }^{2}$ Finally, of special interest in the debate on peer disagreement is the question whether epistemic peers can rationally sustain a disagreement after full disclosure, that is, once they have shared all their relevant evidence as well as announced the respective doxastic attitudes they arrived at.

A growing number of social epistemologists hold that the answers to these questions are negative. In this paper, we point to considerations from the history of science that provide at least some reason for answering the question in the positive. However, we also explain how the other position can appear intuitively attractive.

\footnotetext{
${ }^{1}$ This characterization of the notion of epistemic peer can be found in nearly all recent contributions to the debate about the possibility of rational disagreements. See, e.g., Kelly [2005], Feldman [2006], [2007], Christensen [2007], Douven [2009], [2010], and Goldman [2010].

${ }^{2}$ For present purposes, "doxastic attitude" denotes either outright belief, outright disbelief, or suspension of judgment. Some (e.g., Christensen [2007] and Elga [2007]) have preferred a treatment in terms of degrees of confidence. As will be seen, some of the arguments presented here carry over to the alternative treatment.
} 
1. Scientific disagreements. Considerations from the history of science led Thomas Kuhn [1965:262] to claim that "variability of judgment may . . . be essential to scientific advance." A crucial way in which such variability may matter has to do with the fact that what we perceive tends to be influenced by our expectations, which in turn depend on our theoretical presumptions. ${ }^{3}$ Observations that are odds with these presumptions may therefore simply be overlooked. Moreover, even if observations are not overlooked, they may be dismissed as misleading, perhaps due to measurement errors or confounding factors.

The first point is nicely illustrated by a psychological experiment that Kuhn describes in his [1962/1996:62 ff]. In this experiment, subjects were shown series of playing cards, displayed one at a time, most of which were normal, but some of which were not; for instance, there was a red six of spades and a black four of hearts. While the normal cards were all categorized as such, the abnormal cards were usually categorized as normal as well. When asked, participants who had been shown the black four of hearts would either say that they had seen the four of hearts or the four of spades. As Kuhn points out, this tendency to see what one expects to see manifests itself in science as well. For example, Uranus had been observed many times before it was "officially" discovered as a planet, but on all those previous occasions it had been categorized as a star (even though with hindsight one would say that, from the celestial object's movements, it should have been clear that it was not a star).

The history of thinking about peptic ulcer disease in the community of medical researchers provides an equally nice illustration of the second point. It is currently accepted that peptic ulcer disease is caused by a bacterial infection. However, for a long time, evidence suggesting as much was simply dismissed, due to the fact that medical researchers had been largely convinced by a single, and as later turned out poorly conducted, study that seemed to indicate that no bacteria were to be found in the stomachs of patients suffering from the disease. ${ }^{4}$

So, a certain diversity in the views held by scientists would seem to increase the chances of scientific progress by decreasing the chance that some-potentially crucial—evidence is missed by all groups of researchers.

There are further reasons in favor of this kind of epistemic diversity in the scientific community. As Kuhn [1977:332] observes, before a scientific community decides to accept a new theory, that theory "has been tested over time by the research of a number of men, some working within it, others within its traditional rival," and, he then argues, "[s]uch a mode of development ... requires a decision process which permits rational men to disagree ...." In a similar vein, Popper [1975:87] suggests that

A limited amount of dogmatism is necessary for progress. Without a serious struggle for survival in which the old theories are tenaciously defended, none of the competing theories can show their mettle.

Being challenged by one's peers, be it directly—because they question one's own theory —or indirectly — because they put forth a rival theory—helps to think hard about the comparative virtues and vices of one's theory. More generally, it might be said that this kind of disagreement flags pressing research problems and thereby focuses research and attracts the attention of new scientists. ${ }^{5}$

The variability of judgment Kuhn points at, as well as the dogmatism and tenacious defense Popper deems necessary for progress, would probably be irrational if disagreements among peers were generally irrational. Surely, however, it would go too far to dismiss as

\footnotetext{
${ }^{3}$ A point that was also forcefully argued for in Hanson [1958].

${ }^{4}$ See Thagard [1998a], [1998b] for a detailed account of the development of thinking about peptic ulcer disease.

${ }^{5}$ See on this also Lugg [1978:286f].
} 
irrational what—assuming the above authors are right—are necessary conditions for scientific progress.

In fact, much the same considerations may apply to areas other than science-such as, for instance, philosophy and politics-in that disagreements may contribute to intellectual progress in these areas as well. ${ }^{6}$ From an epistemic point of view, then, it is a good thing that participants to debates in these areas disagree. What is more, it is a good thing for them to do so even once they are appraised of the fact that some of their colleagues, whom they consider peers, have contrary beliefs. If William Alston [1985:70] is right and to have justification for a belief just is for it to be a good thing from an epistemic point of view, then the above considerations provide reason to believe that rational peer disagreement is possible.

On the other hand, it has recently been argued that there is a sense in which it is impossible to rationally sustain disagreements - at least after full disclosure. Suppose pro and con are both leading experts in some field of research. While they both take each other to be peers on a certain question, $Q$, they disagree on what the correct answer to this question is. pro thinks it is $P$, con thinks it is (something entailing) the negation of $P{ }^{7}$ There is a powerful intuition that the rational thing to do here is to suspend judgment on $Q$ and, correlatively, not rational to continue to believe as they do. ${ }^{8}$ This intuition is backed by the observation that if the parties to the disagreement were entitled to hold on to their respective beliefs, they would also be entitled to discount their opponent's opinion simply on the grounds that a disagreement has occurred. Certainly, however, there exists no such entitlement. One cannot discount the opinion of someone one takes to be a peer on some question simply on the basis that a disagreement has occurred. ${ }^{9}$

Does the difference between the two views boil down to a difference over what constitutes epistemic justification? Recall that we used Alston's conception, according to which justification is what is good from an epistemic point of view, to argue that the doxastic attitudes of disagreeing peers can both be justified. As opposed to that, the above argument appeals to the absence of an entitlement - of an epistemic permission — to discount one's peer's opinion. Thus, this argument appears to presuppose a deontological conception of justification, according to which justification depends on what the agent is epistemically permitted to believe. We would not want the difference between the two views to boil down to a difference in conceptions of epistemic justification. In particular, we think that the fact that it is good, from an epistemic point of view, for the parties to a disagreement to hold on to their beliefs will support a claim to the justifiability of these beliefs only if it is strong enough to generate an epistemic permission to do so. In what follows we will show how this can be done. ${ }^{10}$

2. The dynamic approach. To begin with, notice that the problem of rational peer disagreement is typically stated as a static one typically involving two peers who share the same evidence yet hold different doxastic attitudes and know this to be the case. We agree that

\footnotetext{
${ }^{6}$ It is not clear that those considerations apply quite generally. We expect from scientists that they are able to critically reflect upon their own proposals. We do not have the same expectation of, say, religious people.

${ }^{7}$ Notice that this is not the only way in which two agents can disagree. After all, it may also be that one agent suspends judgment while the other holds a belief (disbelief). For convenience's sake, we will often restrict our focus to cases in which the parties to the disagreement hold contrary beliefs.

${ }^{8}$ This view has been defended by Richard Feldman (see his [2005], [2006], [2007], [2009]). The corresponding view that those who have treated the issue in terms of degrees of confidence is the so-called equal weight view, which requires that one give equal weight to the opinion of a peer (Elga [2007:478]).

${ }^{9}$ This, we take it, is the core point of Elga's [2007, Sect. 10] bootstrapping argument.

${ }^{10}$ Notice that we are not alone in favoring this alternative. Among its more prominent champions are Gideon Rosen [2001], Peter van Inwagen [1996], and Ralph Wedgwood [2007].
} 
in the static setup, there is a strong intuition that upon discovering that one's peer holds a different doxastic attitude, one should move one's own attitude in the direction of the peer's. At the same time, at least for the types of disagreement presently under consideration, the static setup is highly unrealistic. It is much more plausible to assume that such disagreements are generated, sustained and resolved in a continuous exchange of reasons and arguments. Otherwise put, a more realistic setup of the problem is dynamic. What we will show is that abandoning the static setup in favor of the dynamic setup of the problem already renders the idea that there can be rational disagreements among peers much more plausible.

Let us start spelling out the dynamic setup of the problem by distinguishing between two types of rounds. In the first type of round, each agent may gather new evidence and evaluates his epistemic state. We will refer to rounds of this kind as deliberative rounds. In the second type of round, each agent discloses the relevant reasons and arguments as well as the conclusion (the doxastic attitude) of the last deliberative round. Rounds of this type shall be labeled disclosive. A debate or dispute can then be understood as a series of rounds starting from a deliberative one, $D_{0}$, and then alternating between disclosive- $D_{1}, D_{3}$, etc.and deliberative $-D_{2}, D_{4}$, etc. - rounds. We have a disagreement at a round, $D_{i}$, just in case at least two parties hold different doxastic attitudes at $D_{i}$. For simplicity's sake, we will assume (i) that the participants to the dispute deliberate and disclose simultaneously, (ii) that, in disclosive rounds, each party to the dispute is exposed to what the other parties have to say, and (iii) that there is the relevant uptake on the part of the parties. For any $i \in\{2,4,6, \ldots\}$, each party's epistemic state in deliberative round $D_{i}$ will include the evidence that led to the formation of the doxastic attitude, the fact that the other parties to the debate hold a certain doxastic attitude, and that they do so on the basis of a number of considerations they take to support their doxastic attitude as well as any further evidence gathered during the round.

It is far from clear that at the end of a given deliberative round, disagreeing peers epistemically ought to suspend judgment. On the contrary, intuitively, one will be entitled to hold onto one's doxastic attitude provided one

(S1) finds reasons to resist the peer's case in favour of his conclusion, and/or

(S2) discovers new evidence in support of one's own belief, and/or

(S3) is able to explain how one's peer could have become involved in error.

In many disputes, certainly in many philosophical ones, the parties to the dispute will combine a number of these strategies at any deliberative round. The results are then presented in the ensuing disclosive round and the disputants' epistemic states will be expanded by the relevant facts about their peer's beliefs as they move on to the next deliberative round. It can easily be seen how any number of peers may be able to sustain a disagreement rationally over an extended number of rounds. At least in this sense, we claim, epistemic peers can sustain rational disagreements.

3. Objections and replies. Some might object to our account of the possibility of rational peer disagreement along the following lines: It is not the case that when the disputants enter a deliberative round, they are entitled to hold onto their doxastic attitudes. Rather, in view of the fact that they are having a disagreement with someone they take to be a peer, they ought to suspend judgment at least until they have evaluated the evidence again. After all, not doing so amounts to dismissing, even if only temporarily, a peer's opinion simply on the grounds that a disagreement has occurred. And, it has already been pointed out, this cannot permissibly be done. 
There are a number of points we would like to make by way of response to this objection. To begin with, it is far from clear that this objection can retain full cogency in the dynamic setup. There are ways of spelling out the details of the case in such a way as to allow the participants to the dispute to hold onto their doxastic attitudes whilst not discounting their peers' opinions in this objectionable way. Here is one way in which this can be done. Suppose the agents' communication procedure is highly ritualized: At each deliberative round agents put their reasons/arguments and conclusions into writing. Copies of all pieces are distributed to each agent who upon completion of reading them enters the next deliberative round. The only access to the other agents' thoughts is through the copies of the written work distributed at disclosive rounds. Suppose upon reading their peers' works, each agent comes to have a strong intuition that something is wrong with the peers' arguments. Suppose, furthermore, that these intuitions are borne out: each agent manages to find reasons to resist their peers' case against their own preferred view. In this situation, it seems quite plausible that the intuition entitles the agents to hold on to their own doxastic attitudes even at the beginning of a deliberative round. (Certainly, the force of this intuition cannot be neutralized by the fact that the peers have a parallel intuition, as one cannot access this fact until the next disclosive round.) In this setup, again, disagreements can be rationally sustained among epistemic peers.

Of course, it is not hard to see how to extend the lesson this case suggests to cases in which agents communicate in more familiar ways. If, for instance, the agents' relevant computational powers were sufficiently increased, they may see straightaway what, according to them, is wrong with their peer's argument. In this case, again, it looks as though rational disagreement among peers is possible. The cases thus suggest that rational peer disagreement can be made possible by adding further details to the description of the relevant cases such as the communication procedure or the agents' computational powers.

We take it that these cases establish the possibility of rational peer disagreement. What they do not establish, however, is that there can be rational disagreements among normal human peers, who do not communicate in the ritualized way and who are not gifted with computational superpowers. ${ }^{11}$ We shall remedy this shortcoming now. To begin with, consider two types of database that are designed to store as many truths about a certain subject matter as possible. They can acquire new data either by interacting with other databases or else by having them entered independently. The first type is designed not to allow conflicts between stored data and data acquired by other databases. As soon as the conflict arises it moves to a state of suspension of judgment and then reevaluates the totality of the data. As opposed to that, the second type is designed to allow in principle for such conflicts but to work towards resolving them when they arise. Is one of the two types of database rationally preferable to the other? Some reason to think that the answer is no here is that, on the face of it, both types of database may well be equally likely to get the job done. ${ }^{12}$

In view of this case, one may start to wonder whether what really matters here is that, upon entering a deliberative round, one suspends judgment rather than continues to believe. Our suspicion is that it is not. Accordingly, we do not find it a priori problematic to grant agents a permission to hold onto their beliefs when entering a deliberative round. Rather, what really matters is that one does not continue to believe unless one manages to engage

\footnotetext{
${ }^{11}$ For the record, we think that scholarly disputes often approximate the ritualized way of communication closely enough.

${ }^{12}$ Notice that the two databases differ from the communities of agents modelled in Douven [2010], which adopt different policies to deal with disagreements, to wit, "sticking to their guns" and "splitting the difference," respectively. After all, even the tension-resolving database may come to the conclusion that the right thing to do is to split the difference.
} 
with one's peers' views in a satisfactory manner. For that reason the permission to continue to believe should not be granted "willynilly." Tied to it are (at least) the following duties:

(D1) A duty towards one's peers to engage with their views (for instance, in one of the ways outlined in (S1)-(S3) above).

(D2) A duty to suspend judgment if it turns out that one cannot adequately discharge the duty stated in (D1).

It becomes clear that, on this view, the parties to rational peer disagreements do not discount their opponents' views simply on the basis that a disagreement has occurred. Rather, they discount them conditional on engaging with them in satisfactory ways and will move to suspension of judgment if they fail to do so.

For these reasons we believe that there is no a priori reason against granting parties to a disagreement the permission to continue to hold onto their doxastic attitudes when entering a deliberative round. At the same time, we think that what the agent ought to believe upon entering a deliberative round may hinge on further a posteriori facts. To see this, suppose, first, that (some of) the agents involved are so constituted that they easily lose interest in a question once they suspend judgment on it, but will continue to think very hard about the matter so long as they continue to hold a belief. Alternatively, suppose that the agent community will lose interest in the question if one particular member does and this latter agent is constituted as described above. (Consider: The head of a research group loses interest in a certain question and as a result so does the rest of the group.) Since, the agents will make no progress on arriving at the truth on the question unless they continue to think about it, their holding on to their doxastic attitudes may well be the thing to do here. ${ }^{13}$

On the other hand, suppose that the agents involved are prone to take their peers' views more lightheartedly if they hold onto their beliefs, whilst, at the same time, their continued interest is not dependent on their continued believing. In this case, it would seem that suspension of judgment (upon entering a deliberative round) is what the agents ought to do. Of course, these are just two types of a posteriori fact that play a part in determining whether, in the situations under consideration, a given agent ought to continue to believe or suspend judgment. Other types of fact may play a part as well. Moreover, things must not be expected to fall as neatly into place as they do in the toy examples. Interest comes in degrees as does taking opponents' views lightheartedly. Accordingly, it must be expected that the various factors will have to be weighed against each other on a case-by-case basis to determine whether, in the types of situation under consideration, a given agent ought to continue to believe or suspend judgment. So, while we think that there is no a priori reason to deny parties to a peer disagreement the permission to hold onto their doxastic attitudes, there will be a host of a posteriori facts that will be of vital importance here. Crucially, however, the a posteriori facts can go both ways. As a result, our case for the possibility of rational peer disagreement even among normal human beings remains in good standing.

4. Other types of disagreement. It is noteworthy that the problem concerning the epistemic status of disagreements is typically understood as a specific problem concerning cases of disagreement among equal numbers of agents (typically two) who are and/or take each other to be peers. Before closing, we would like to make some points regarding disagreements

\footnotetext{
${ }^{13}$ This point is very much in line with the results presented Douven [2010], which stresses the importance of contingent facts to the rationality of disagreements.
} 
among unequal numbers of agents and among agents who are not and do not take each other to be peers.

Let us start with a case in which there is a disagreement among unequal parties of agents who all take each other to be peers. To take an extreme example, suppose that the large party, $L$, counts a hundred members while the small one, $S$, consists of a single agent. Suppose, next, that, in a disclosive round, $S$ presents an argument suggesting that $L$ is mistaken. Surely, the members of $L$ ought not dismiss this argument simply on the basis that they do not agree with its conclusion. After all, even large groups of people can be mistaken. Similarly, suppose someone one considers one's inferior on a given question presents one with an argument suggesting that one is mistaken. In this situation, one ought not dismiss this argument simply on the basis that one does not agree with it either. After all, the epistemically most superior among us are fallible and even the epistemically vastly inferior can have lucky breaks.

These cases suggest that the sorts of consideration that have driven some to deny the possibility of rational disagreement among equal parties of peers can be adapted to support parallel conclusions for disagreements among unequal parties of peers and disagreements among non-peers. Contrary to what appears to be received wisdom, the problem of rational peer disagreement is not specific to peers-never mind to equal parties of peers-after all.

The present dynamic approach to the problem of peer disagreement can handle these other types of disagreement, too. In fact, it can provide a uniform account for all of these types of disagreement, namely, the parties involved can rationally sustain disagreements over a series of rounds, for instance, if all parties successfully deploy some of the strategies (S1)(S3) mentioned above. Moreover, there is no a priori problem with granting the parties a permission to continue to believe provided that they discharge the relevant duties (including (D1) and (D2)). At the same time, a posteriori facts may generate obligations to react to the disagreement in a specific way. All of this holds equally for the type of case that has been the focus in the literature and the variations currently under consideration.

This, we claim, is a benefit of the dynamic approach. After all, intuitively, there can be rational disagreements of the kinds described. Regarding disagreements among unequal parties of peers consider disagreements among scientists before a paradigm shift. Intuitively, the scientists who accept the new paradigm are often rational in so doing even when they are by far outnumbered by disagreeing peers. For instance, intuitively, Copernicus was rational in accepting the heliocentric system even when the vast majority of his peers disagreed with him. Regarding disagreements among non-peers, consider disagreements among current leading figures on a certain question and the most promising young scholars. While the leading figure may be generally regarded as the young scholar's superior-if only because he has had much more time to think about the issue and become acquainted with the relevant literature-a disagreement between them may still be rational. A nice illustration of this is provided by De Regt [1996], who describes the dispute between Maxwell and Boltzmann about Boltzmann's explanation of a certain anomaly - the specific heat anomaly, as it was called - in the kinetic theory of gases. Maxwell, the leading figure in the field, and Boltzmann, who was Maxwell's junior by thirteen years, both stuck to their guns in their exchange about the anomaly.

The dynamic approach can make sense of how Maxwell and Boltzmann can have beenand more generally how parties to the designated type of disagreements can be-rational in their respective beliefs in the way sketched above. It thus secures an additional advantage over a number of alternative approaches to the problem of disagreement-most notably, of 
course, over those that claim that rational disagreements are impossible even among equal parties of peers. ${ }^{14}$

\section{References}

Alston, W. [1985] “Concepts of Epistemic Justification,” The Monist 68:57-89.

Christensen, D. [2007] "Epistemology of Disagreement: The Good News," Philosophical Review 116:187-217.

De Regt, H. W. [1996] "Philosophy and the Kinetic Theory of Gases," British Journal for the Philosophy of Science 47:31-62.

Douven, I. [2009] “Uniqueness Revisited," American Philosophical Quarterly 46:347-361.

Douven, I. [2010] "Simulating Peer Disagreements," Studies in History and Philosophy of Science 41:148-157.

Elga, A. [2007] "Reflection and Disagreement," Noûs 41:478-502.

Feldman, R. [2005] “Respecting the Evidence," Philosophical Perspectives 19:95-119.

Feldman, R. [2006] "Epistemological Puzzles about Disagreement," in S. Hetherington (ed.) Epistemology Futures, Oxford: Oxford University Press, pp. 216-236.

Feldman, R. [2007] “Reasonable Religious Disagreements,” in L. Antony (ed.) Philosophers Without Gods: Meditations on Atheism and the Secular Life, Oxford: Oxford University Press, pp. 194-214.

Feldman, R. [2009] "Evidentialism, Higher-Order Evidence, and Disagreement," Episteme 6:294-312.

Goldman, A. I. [1999] Knowledge in a Social World, Oxford: Oxford University Press.

Goldman, A. I. [2010] "Epistemic Relativism and Reasonable Disagreement," in R. Feldman and T. Warfield (eds.) Disagreement, Oxford: Oxford University Press, in press.

Hanson, N.R. [1958] Patterns of Discovery, Cambridge: Cambridge University Press.

Kelly, T. [2005] "The Epistemic Significance of Disagreement," Oxford Studies in Epistemology 1:167-197.

Kuhn, T. [1962/1996] The Structure of Scientific Revolutions (3rd ed.), Chicago: Chicago University Press.

Lakatos, I. [1978] The Methodology of Scientific Research Programmes (Philosophical Papers, Vol. I, edited by J. Worrall and G. Currie), Cambridge: Cambridge University Press.

Lugg, A. [1978] "Disagreement in Science," Journal for General Philosophy of Science 9:276-292.

Popper, K. R. [1975] “The Rationality of Scientific Revolutions,” in R. Harré (ed.) Scientific Revolutions: Progress and Obstacles to Progress, Oxford: Clarendon Press, pp. 72101.

Rosen, G. [2001] “Nominalism, Naturalism, Philosophical Relativism,” Philosophical Perspectives 15:69-91.

Thagard, P. [1998a] “Ulcers and Bacteria I: Discovery and Acceptance," Studies in History and Philosophy of Biology and Biomedical Sciences 29:107-136.

Thagard, P. [1998b] "Ulcers and Bacteria II: Instruments, Experiments and Social Interactions," Studies in History and Philosophy of Biology and Biomedical Sciences 29:317342.

\footnotetext{
${ }^{14}$ We are indebted to Henk de Regt and Fred Muller for valuable discussions on the topic of this paper.
} 
van Inwagen, P. [1996] "It's Wrong, Always, Everywhere, and for Anyone, to Believe Anything, Upon Insufficient Evidence," in J. Jordan and D. Howard-Snyder (eds.) Faith, Freedom, and Rationality, Lanham MD: Rowman and Littlefield, pp. 137-154.

Wedgwood, R. [2007] The Nature of Normativity, Oxford: Oxford University Press. 